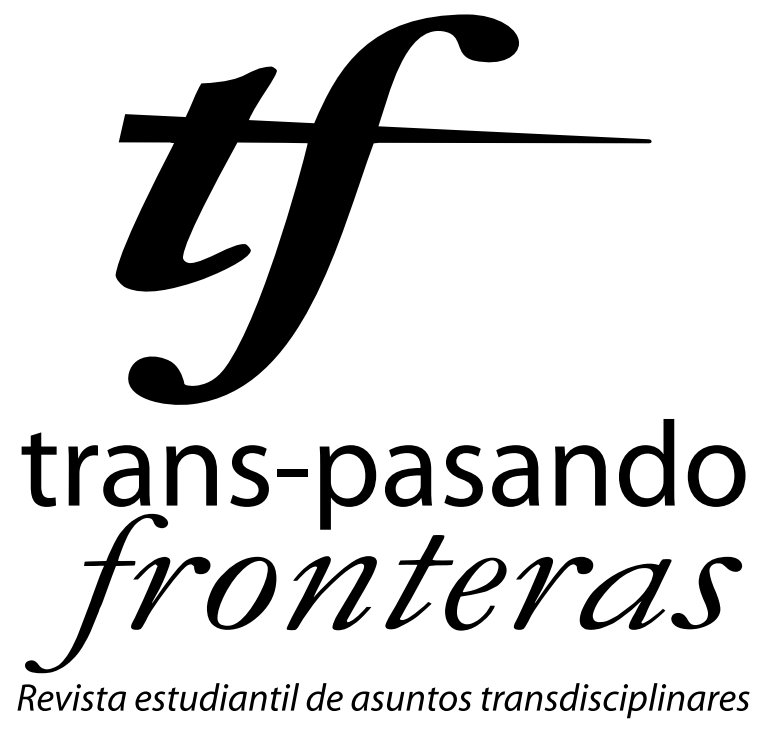

Una publicación de

Facultad de Derecho y Ciencias Sociales

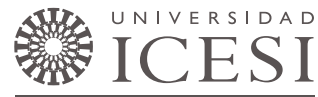




\title{
Un mundo incierto
}

\author{
Alejandra Oviedo \\ (aleja.oc@hotmail.com)
}

WALLERSTEIN, Immanuel (2005). Un mundo incierto. Buenos Aires: Libros del Zorzal, 2005. 100 páginas.

El sociólogo estadounidense Immanuel Wallerstein (Nueva York, 1930), es el principal teórico del análisis del sistema-mundo. A través de diversas publicaciones como Después del liberalismo (1996), Abrir las ciencias sociales (1996), El futuro de la civilización capitalista (1997), La decadencia del poder estadounidense. Estados Unidos en un mundo caótico (2005) y Análisis de sistemas-mundo. Una introducción (2006), Wallerstein refleja su interés por explicar la realidad contemporánea.

El libro Un mundo incierto fue escrito en el 2005 dentro de un periodo, considerado por algunos estudiosos del sistema internacional, de transición e incertidumbre en el ámbito internacional por abarcar acontecimientos influyentes de finales del siglo XX y comienzos del XXI. Entre los hechos internacionales se resaltan: el 11 de septiembre de 2001, cuando el país considerado potencia hegemónica, Estados Unidos, fue objeto de un ataque por parte de la organización terrorista islámica al Qaeda; en octubre del mismo año EE.UU. invade Afganistán con el objetivo de capturar a Osama Bin Laden. En el 2002 entra a regir el euro como moneda única en doce países de la Unión Europea; un año más tarde, con el pretexto de la existencia de artefactos de destrucción masiva, EE.UU. entra a Irak; en los siguientes dos años, países europeos como España e Inglaterra son objeto de ataques terroristas. Del año 2005 es importante señalar el rechazo a la constitución de la Unión Europea tras un referéndum popular realizado en Francia y 
Holanda, y la retirada de la tropas de Gaza por parte Israel (Xinhuanet, 2005).

En relación a la estructura del texto, Un mundo incierto consta de dos partes en las cuales el autor señala acontecimientos mundiales que han sido de gran relevancia en la esfera internacional y objeto de análisis de los estudiosos de la disciplina de las Relaciones Internacionales.

La primera parte, La actualidad vista desde la larga duración, se divide en nueve capítulos; en ellos trata centralmente algunos retos claves que las relaciones internacionales han tenido que explicar como el papel que juegan los movimientos antisistema en la esfera política mundial, temas sensibles de la Unión Europea como el intento de consagrar un marco jurídico-político vinculante para los Estados miembros, el rol de la Organización del Tratado Atlántico Norte (OTAN) en el escenario mundial actual, el conflicto entre israelíes y palestinos, el declive de Estados Unidos como hegemonía mundial, y su relación con India y China, de donde ha obtenido ganancias a cambio del reconocimiento de India como actor militar mundial y China como actor financiero; entre otros.

En la segunda parte, Los Intelectuales en una transición, el autor afirma que el mundo que conocemos es el de una economía-mundo capitalista que se encuentra en crisis y que, en su búsqueda por instalar un nuevo orden, está transitando de un sistema a otro. En este proceso los intelectuales deben aportar sus pensamientos para explicar los acontecimientos y la transición del sistema-mundo moderno $^{1}$, en especial, para hacer explicitas las opciones que nos ofrece individual y colectivamente (Wallerstein, 2005:93).

\section{Desafíos de las relaciones internacionales} Wallerstein identifica, a partir del análisis del sistema-mundo actual, los desafíos más importantes que deben enfrentar las relaciones internacionales. Afirma que los intelectuales deberán jugar un papel preponderante pues, como señala el autor en la parte final del libro, "el resultado de la lucha es muy incierto; pero en las eras de transición nadie puede darse el lujo de quedarse al margen" (Wallerstein, 2005:100).

El atentado terrorista del 11 de septiembre provoca un cambio de imagen hacia Estados Unidos, específicamente,

1 Para Wallerstein, el sistema-mundo es un sistema social que tiene fronteras, estructuras, grupos miembros, reglas de legitimación y coherencia, donde cada grupo busca su propia ventaja. 
sobre su percepción como Estado fuerte, como centro de poder en las relaciones internacionales; es a partir de allí que se empieza a disminuir su presencia en la arena internacional. Dicho suceso hace que se empiece a percibir a los Estados Unidos como una potencia hegemónica en decadencia pues, desde un posicionamiento unilateral, este país ya no logra definir las reglas del juego geopolítico mundial.

La posición asumida por israelíes y palestinos es sin duda uno de los mayores retos para las relaciones internacionales, pues existe una disputa entre dos movimientos nacionalistas por un mismo territorio, disputa que podría dejar como resultado, según el autor, "una guerra química".

Por otro lado, desde esta disciplina se debe explicar cómo las políticas que adopta un gobernante pueden cambiar su posición en la escena mundial. Rusia es un ejemplo de esto. Antes del año 2000 el nivel de vida de sus ciudadanos era considerada como crítico; a nivel internacional, era menospreciado, entre otros países, por EE.UU pero la llegada de Vladimir Putin al poder político de ese país, según Wallerstein, logró cambiar ese panorama. Lo primero que hizo el mandatario ruso fue mejorar la gestión de la política doméstica y luego fortalecer su política exterior. Sacó ventaja del atentado del 11 de septiembre brindando ayuda a los estadounidenses en su lucha contra el terrorismo, por lo que logró anular o retrasar el proyecto antimisiles. Estas políticas regeneraron el perfil de Rusia frente al mundo después del desplome de la URSS, devolviéndole un papel protagónico en la escena geopolítica mundial.

Actualmente, los Estados soberanos siguen siendo el elemento principal del sistema político internacional pero, a causa de la democratización del mundo, han tenido que responder a unas presiones estructurales representadas muchas veces en movimientos antisistema (Wallerstein, 2005:71).

El Foro Social Mundial congrega movimientos del Norte y del Sur, reúne sectores históricos de la izquierda mundial que "comparten el hecho de estar en activa oposición al neoliberalismo" (Wallerstein, 2005:47). Se han celebrado varias reuniones y con el paso del tiempo y de las crisis sociopolíticas de la actual economía mundial, han adquirido cada vez más fuerza. A grandes rasgos lo que pretendían los movimientos antisistema, como los reunidos en el Foro o los Zapatistas en México, era conquistar el poder 
del Estado bajo cualquier medio, esto con el fin de cambiar las condiciones sociales. Para ello crearó una estructura organizativa centralizada llamada "estrategia de los dos pasos", que consistía, primero, en alcanzar el poder, condición exitosa en muchos casos; sin embargo, el segundo paso nunca ocurrió, pues fueron incapaces de transformar las cosas (Wallerstein, 2005:46).

\section{Predecir sobre incertidumbres}

El libro no se puede reducir a una sola ciencia social, por lo contrario, su explicación de los cambios ocurridos en el mundo no se apoya únicamente en la perspectiva histórica, sino también en la disertación internacional, económica, política y sociológica.

En este sentido, se puede decir que la búsqueda por abarcar la realidad contemporánea responde unas dinámicas transdisciplinares, las cuales ocurren, según Lewis Gordon (2011), “cuando las disciplinas se comunican por el bien de la realidad, lo cual puede significar la creación de nuevas disciplinas". Lo anterior, se asocia con la necesidad de tratar las relaciones internacionales como campo de estudio per se. En palabras de Arenal (1981) “por la necesidad de aprehensión global de la compleja realidad internacional, con el objetivo central de superar planteamientos ya insuficientes $y$ dar respuesta los complejos problemas internacionales".

Actualmente llevamos a cabo una indagación por entender los constantes cambios y transformaciones sociales, económicas y políticas mundiales. En este sentido, la obra de Wallerstein nos ofrece significativos aportes para comprenderlos a partir de un exhaustivo y profundo análisis del sistema mundial, partiendo de acontecimientos y procesos concretos como rol internacional del Foro Social Mundial o Los Zapatistas.

La importancia de este libro radica en que a partir de hechos protagónicos se da cuenta de la forma de organización de las relaciones internacionales y de aquello que está en juego en las relaciones entre diferentes Estados y organizaciones. Además, plantea lo que entonces serían los futuros escenarios, los escenarios de hoy, que a siete años de la publicación del texto, nos permite aseverar la certeza de sus pronósticos. Por ejemplo, Wallerstein enunció que si la pelea entre Estados Unidos y Bin Laden terminara en empate, el gran ganador sería el último al no contar con los mismos recursos del gobierno del primero. 
Hoy, tras culminada la invasión de Estados Unidos a Afganistán, el balance para el país es negativo; en virtud a la pérdida de credibilidad por parte de otros Estados. A pesar de lo enunciado anteriormente, Estados Unidos, según Wallerstein, sigue y seguirá siendo, al menos por los próximos veinte años, la potencia hegemónica en declive, no sólo por su propio sistema, sino también por la crisis que atraviesa todo el sistema-mundo.

Como ya se mencionó, estamos insertos en un mundo incierto y como tal, la respuesta a cuál será el futuro del sistema internacional lo es también. Por suerte, el libro Un mundo incierto escrito por Wallerstein, ayuda a iluminar el camino para encontrar esta respuesta.

\section{Referencias}

ARENAL, Celestino (1981). "La génesis de las relaciones internacionales como disciplina científica”. En: Estudios Internacionales, vol. 2, núm. 4, pp. 849892 , octubre-diciembre.

GORDON, Lewis (2010). "Manifiesto de transdisciplinariedad. Para no volvernos esclavos del conocimiento de otros". En: Trans-pasando Fronteras, Núm. 1, octubre de 2010. Cali, Universidad Icesi.
WALLERSTEIN, Immanuel (1974). The modern World System I: Capitalist Agriculture and the Origins of the European World-Economy in the Sixteenth Century. New York, Academic Press.

XINHUA (2005). 10 noticias internacionales más importantes de 2005 seleccionadas por Xinhua. Recuperado el 10 de mayo de 2012 desde de www.spanish. xinhuanet.com/spanish/2005-12/30/content_20 0182.htm 